\title{
Vibrio parahaemolyticus: a review on the pathogenicity, antibiotic resistance, foodborne outbreaks, and detection methods
}

\author{
${ }^{1}$ Naziahsalam Kehinde, A., ${ }^{1, *}$ Tang, J.Y.H. and ${ }^{2}$ Nakaguchi, Y. \\ ${ }^{1}$ Faculty of Bioresources and Food Industry, School of Food Industry, Universiti Sultan Zainal Abidin, \\ 22200, Besut, Terengganu \\ ${ }^{2}$ Center for Southeast Asian Studies, Kyoto University, Kyoto, Japan
}

\begin{abstract}
Article history:
Received: 4 September 2020

Received in revised form: 15 October 2020

Accepted: 30 November 2020

Available Online: 14 March 2021
\end{abstract}

\section{Keywords:}

Vibrio parahaemolyticus,

Seafood,

Pathogenicity,

Antibiotics resistance,

Outbreaks,

Detections

DOI:

https://doi.org/10.26656/fr.2017.5(3).479

\begin{abstract}
Vibrio parahaemolyticus is a Gram-negative bacterium that is a natural inhabitant of the marine habitat. $V$. parahaemolyticus is a human foodborne pathogen linked to the consumption of contaminated raw and undercooked seafood. $V$. parahaemolyticus pathogenicity has been linked to the presence of two virulence gene that is thermostable direct hemolysin $(t d h)$ and TDH-related hemolysin (trh). The emergence of antibiotic resistant strain of $V$. parahaemolyticus is a menace to public health. $V$. parahaemolyticus is linked to several foodborne diseases in Asian countries including Japan, China and Taiwan and has been acknowledged as the major cause of human gastroenteritis in the United States. The emergence of pathogenic Vibrio species in shellfish in Malaysia requires persistent monitoring and public enlightenment on food safety. Several detection methods based on its virulence factors are used in detecting $V$. parahaemolyticus. This review will provide an insight on $V$. parahaemolyticus, its pathogenicity, antibiotic resistance, foodborne outbreaks and detection methods.
\end{abstract}

\section{Introduction}

Vibrio parahaemolyticus belongs to the Vibrionaceae family. They are Gram-negative, ubiquitous, halophilic facultative anaerobic bacteria found in marine, estuarine environments that are positive to the biochemical test catalase and oxidase. They can survive at a temperature between $5^{\circ} \mathrm{C}$ and $43^{\circ} \mathrm{C}$ and are grown optimally at $37^{\circ} \mathrm{C}$. The Vibrio genus consists of 142 species that are mainly found in the marine environment (Sawabe et al., 2013). V. parahaemolyticus is capable of causing infection in human. $V$. parahaemolyticus uses flagella to move freely in water or fixed to an animate object such as a shellfish (Godepotratz et al., 2011). V. parahaemolyticus possesses a dual flagella system which helps them adapt to the different environment. The polar flagella help with movement while the lateral flagella involved in biofilm formation (Broberg et al., 2011). V. parahaemolyticus is regarded as the most prevalent pathogen associated with seafood and many outbreaks have occurred worldwide as a result of ingestion of raw and undercooked seafood which resulted in the inflammation of the bowel. The availability of this pathogenic bacteria in the marine habitat should be a great concern to humans due to the consistent outbreak of the disease (Ceccarelli et al.,
2013). V. parahaemolyticus causes infection by attaching itself to the fibronectin and phosphatidic acid on the host cell thereby unleashing different toxins into the cytoplasm of the host cell and this will lead to a lifethreatening illness (Gode-Potratz et al., 2011). V. parahaemolyticus was first discovered in the 1950s in Japan as a foodborne disease with a huge outbreak originating from the prevalent serotype O3:K6 from 1997 to 2001 (Hara-Kudo et al., 2012). Several studies have reported a high prevalence of $V$. parahaemolyticus in shellfish in Malaysia (Al-Othrubi et al., 2014; Sahilah et al., 2014; Tang et al., 2014; Malcolm et al., 2015). V. parahaemolyticus has been reported as the major causative agent of seafood associated gastroenteritis in several countries such as the United States and Asian countries (Scallan et al., 2011).

\section{Pathogenicity of Vibrio parahaemolyticus}

It is a known fact that a great number of $V$. parahaemolyticus strains detected from environmental samples are not pathogenic. A great number of the pathogenic $V$. parahaemolyticus are isolated from clinical samples. $V$. parahaemolyticus is capable of producing three hemolysins; thermostable direct hemolysin (TDH), TDH-related hemolysin (TRH) and 
thermolabile hemolysin (TLH) encoded by the $t d h$, trh and $t$ th genes (Paranjype et al., 2012). The pathogenicity of $V$. parahaemolyticus is dependent on their ability to produce the virulent gene thermostable direct hemolysin $(t d h)$ and thermostable direct hemolysin related hemolysin (trh) (Gutierrez West et al., 2013). The T3SS1 guarantee the survival of $V$. parahaemolyticus strain in its habitat. In addition, the T3SS1 are capable of causing damage to the infected host cell thus essential nutrients are released (Paranjpye et al., 2012). The thermolabile hemolysin (TLH) is another type of hemolysin encoded by the $t$ th gene and also causes the breakdown of red blood cells (Wang, Xiang, Feng et al., 2013). The $t$ th gene also causes the breakdown of human erythrocytes (Broberg et al., 2011). Aside $V$. parahaemolyticus possessing the virulence gene which increases its pathogenicity, the presence of the flagella for its movement also contributes to the pathogenicity because it is able to produce a capsule thereby helping the pathogen move freely and survive in its habitat and a human host (Broberg et al., 2011).

\subsection{Pathogen fixation to the host cell}

The ability of the bacteria to fix itself into the host cell is a crucial step in which disease develops. $V$. parahaemolyticus is capable of binding to several host cells such as epithelial cell, fibroblasts and macrophages (Stones and Krachler, 2015) due to the presence of the multivalent adhesion molecule 7 (MAM7) found in many Gram-negative bacteria (Krachler et al., 2011). The MAM7 is made up of a water-repelling stretch of 44 amino acids at its $\mathrm{N}$ terminus (Letchumanan et al., 2014) MAM7 consists of two host surface receptor which is; host membrane phosphatidic acid lipids (PA) which helps the bacteria bind firmly to its host cell and the extracellular matrix protein fibronectin which acts as a co-receptor to enhance the entry of the pathogen to the host cell (Lim et al., 2014) MAM7 is made up of seven mammalian cell entry domain and all seven possess the PA binding (Lim et al., 2014). When MAM7 bind to fibronectin and PA, an obstruction can occur during the fixation of MAM7 to the host cell if one of the surface receptors is blocked. Furthermore, MAM7 is important for primary host binding once the disease occurs and for T3SS- mediated cell death in some cell types. This information on MAM7 gives an insight on the relationship between bacterial and host cell (Krachler et al., 2011). T3SS is important for the pathogenicity of different Gram-negative bacteria and mainly used by the bacteria for its growth and survival inside the host cell (Dean, 2011). T3SS uses a needle-like apparatus to transfer toxins and bacterial proteins also called effectors into the host cells thereby targeting and hijacking several eukaryotic signalling pathways. The release of these effectors from bacteria is caused as a result of contact between the bacteria and host (Dean, 2011).

\subsection{Toxins produced by Vibrio parahaemolyticus}

$V$. parahaemolyticus exhibit different virulence factors such as the production of toxins which increases their chances of causing gastrointestinal infection (Liu and Chen, 2015). V. parahaemolyticus are largely found in the marine and coastal habitat but not all strains are virulent (Velazquez-Roman et al., 2012). The thermostable direct hemolysin $(t d h)$ and TDH-related hemolysin (trh) are the main toxins found in $V$. parahaemolyticus. $V$. parahaemolyticus becomes virulent when they possess the $t d h$ and trh gene which are responsible for hemolysis and cytotoxicity activity in the host cell (Broberg et al., 2011; Zheng et al., 2014). The strains collected from the environmental samples do not possess the $t d h$ and trh gene. Thus, most environmental strains do not cause disease to humans and animals (Gutierrez West et al., 2013). However, studies have shown that even when the $t d h$ and/or trh genes are absent, $V$. parahaemolyticus remains virulent and this shows there are other virulence factors attributed to the bacterium (Jones et al., 2012; Pazhani et al., 2014). Compared to the environmental samples, the clinical samples that cause gastroenteritis in human possess the $t d h$ and $t r h$ gene which are able to break red blood cells on Wagatsuma blood agar. This hemolytic activity is called the Kanagawa phenomenon (KP) (Alipour et al., 2014). Out of all environmental samples, only 1 to $2 \%$ is said to be KP-positive while others are regarded as KP-negative (Alipour et al., 2014). TDH is a toxin that is capable of forming pores on the red blood cells and this allows for free movement of water and ions through the membranes which later leads to swelling of the cell and death in most cases (Raghunath, 2015). The TDH targets the epithelial and intestinal cell thereby causing severe diarrhoea (Shimohata and Takahashi, 2010). TRH is similar to TDH in terms of its hemolytic activity on blood cells (Ham and Orth, 2012) TRH can be destroyed when subjected to heat (Shimohata and Takahashi, 2010) even though it is being reported to be more pathogenic than TDH (Saito et al., 2015). In addition, TLH is another type of toxin that influences the pathogenicity of $V$. parahaemolyticus (Zhao et al., 2011) and it is often referred to as a species-specific marker. The TLH possess the phospholipase activity and are able to break down the human red blood cell (Broberg et al., 2011) Thus, TLH and TDH play a similar role in the pathogenicity of $V$. parahaemolyticus (Wang et al., 2015). V. parahaemolyticus is classified based on the somatic $(\mathrm{O})$ and capsular $(\mathrm{K})$ antigen which is formed in different environmental condition (Nair et al., 2007). Serovar is also used in detecting $V$. parahaemolyticus 
and its pathogenicity. Since $V$. parahaemolyticus is a multi-serovar bacterium that comprises 12 different $\mathrm{O}$ antigens and more than seventy different $\mathrm{K}$ antigens in its capsule (Xu et al., 2014). Out of this serovar, the serovar (O3:K6, O4:K68 and $\mathrm{O} 1: \mathrm{K}$ untypeable) are the most lethal and deadly to humans and are recognized as the main cause of the foodborne disease (Jones et al., 2012). The toxic strains of $V$. parahaemolyticus cause severe inflammation of the bowel and are usually spread through consuming raw or semi-cooked seafood (Zarei et al., 2012). In February 1996, a distinctive serotype O3:K6 of $V$. parahaemolyticus accompanied by a discrete genetic marker instantly occurred in Kolkata, India. Consecutively, a similar serotype isolated from India has been isolated from other foodborne disease outbreak in Southeast Asia, Europe, Africa and the United States (Velazquez-Roman et al., 2014). The prevalent O3:K6 strain was detected in Peru and then spread to Chile in 1998 with over 16,804 occurrences, then to the United States in 1998 with over 700 occurrences than to Brazil in 2001 with more than 18 occurrences and Mexico in 2004 with more than 1200 occurrences (Velazquez-Roman et al., 2014).

\subsection{Emergence of Vibrio parahaemolyticus pandemic clone}

The incidence of $V$. parahaemolyticus occurs irregularly showing no link between distinct serovar of $V$. parahaemolyticus and gastroenteritis (HernandezDiaz et al., 2015). In molecular epidemiological studies, a distinct serovar O3:K6 was isolated from clinical samples (Velazquez-Roman et al., 2012) and this has been a global menace in Africa (Ansaruzzaman et al., 2008), Asia (Li et al., 2016), Europe (Martinez-Urtaza et $a l ., 2005)$ and the United States (Velazquez-Roman et al., 2014). The swift spread of the O3:K6 serovar has made $V$. parahaemolyticus an important foodborne pathogen to the general public worldwide (Ceccarelli et al., 2013). In 2007, several serovars of $V$. parahaemolyticus has been discovered with similar genotypes and molecular profile as the O3:K6 and were termed 'serovariants', in which O4:K68, O1:K25 and O1:KUT are the most common serovar (Nair et al., 2007). V. parahaemolyticus genetic diversity was made easy due to the influence of a multilocus sequence typing (MLST) scheme (González-Escalona et al., 2008). The O3:K6 serovar was able to spread worldwide due to the presence of the open reading frame 8 (orf8) through phage $\mathrm{f} 237$ infection thereby increasing its potency level because the orf 8 protein product influences the ability to be able to bind to the intestine of the host cell (Ceccarelli et al., 2013).

\section{Antibiotic resistance of Vibrio parahaemolyticus}

Antibiotics resistance has now been seen as a global menace to the public health and food industry (FAO, 2016). The continuous use and abuse of antibiotics by humans, in the marine industry, agriculture and livestock have led to the emergence and spread of resistant strains. Also, aside from the antibiotic resistance strains, the multidrug-resistant bacterial strain is another menace because the bacterial becomes resistant to several antibiotics that would have been able to kill or inhibit its growth. The multidrug-resistant bacterial could be a result of chromosomal DNA mutations, enzymatic inactivation, transformation as well as conjugation (Van Hoek et al., 2011). In the marine industry, antibiotics are used indiscriminately in fish farming to enhance the growth of aquatic animals and also reduce the risk of bacterial infection most especially the Vibrio species. Since Vibrio species are mainly inhabitants of the marine environment capable of causing infections in aquatic fish (Sudha et al., 2014). Hence, the continuous use of this antibiotics has led to an increase in the antibiotic resistant strains of Vibrio species (Letchumanan et al., 2015). In fish farming, tetracyclines, erythromycin, sulphonamides, oxytetracyclines, chlortetracycline and amoxicillin are used in some part of Asian including Malaysia, Myanmar and Philippines whereas nitrofurans, chloramphenicol and dimetridazole were banned in most countries (Weese et al., 2015). V. parahaemolyticus infection has been linked to oysters, clams, cockles, mussels, crabs and shrimps (Malcolm et al., 2015). The Malaysian communities are seen as a huge consumer of seafood with an increase of above $40 \mathrm{~kg} /$ capita/ year since 1970 thereby generating a means of income to the fish farmers (Witus and Van, 2016). An increase in the aquaculture industry as a result of the demand for fish has led to a weakened immune system thereby exposing the fish to bacterial infections. Continuous use of antibiotics will increase the resistant strains of Vibrio species (Lee and Raghunath, 2018). Also, these resistant strains can be transferred from human through the consumption of contaminated foods and can also be transferred to other bacteria thereby causing harm to the public (Kim et al., 2013). In recent studies, Carbapenems was reported as the last resort for treating Gram-negative and Gram-positive infections and infections caused by multidrug-resistant bacteria. However, there is an increased occurrence of carbapenem-resistant bacteria (Martin et al., 2018). Carbapenem-resistant Vibrio spp. has been detected from environmental seafood samples (Gu et al., 2014). The consistent increase in antibiotic resistant and multidrug-resistant strain of $V$. parahaemolyticus is an important public health issue (Xie et al., 2017; Syamimi-Hanim and Tang, 2019). However, it is important to gather more knowledge on antimicrobial trends. 


\section{Foodborne outbreak related to Vibrio parahaemolyticus}

A foodborne disease outbreak is a continuous occurrence of the same disease emerging as a result of consumption of the same food. In the United States, about $97 \%$ of the fish and shellfish consumed are imported and this percentage has increased over time. Between 1996 - 2014, about 195 outbreaks were associated with foods imported to the country which led to 10,685 illness, 1,017 hospitalizations and 19 death (USDA, 2016). Also, the Asian countries are most susceptible to the $V$. parahaemolyticus epidemic because the temperature and climate in this region support the development of this bacteria. Recently, the ministry of health has reported a foodborne outbreak in which about $3 \%$ of the disease was linked to $V$. parahaemolyticus (Bilung et al., 2005). Foodborne outbreaks caused by $V$. parahaemolyticus mainly occur in places with high consumption of seafood. In the United States, (Iwamoto et al., 2010) reported an outbreak of the disease via the consumption of undercooked seafood. The infection can occur after consuming food that has been contaminated and the disease gives symptoms such as frequently passing out watery faeces and vomiting (Yeung and Boor, 2004). $V$. parahaemolyticus associated with consumption of raw or improperly cooked seafood commonly occur in summer (Khan et al., 2002). According to the Korean Ministry of food and drug safety, consumption of contaminated seafood has been one of the leading causes of food poisoning. In Korea, $V$. parahaemolyticus outbreak occurs mainly in August and September with just a few cases in June, July and October but in 2004, there was an outbreak of the disease in April and May. There has been an increase in $V$. parahaemolyticus in Canada since 2009 from 0.3/100000 in 2005 to $1.4 / 100000$ in 2014. The reason for the increase remains unknown but it could also be as a result of environmental temperature or a deliberate consumption of raw shellfish. Also, it has been reported in several states in Venezuela an outbreak of $V$. parahaemolyticus leaving $36 \%$ of the people infected hospitalized but no death was recorded (CDC, 2018). Thus, following the detection of $V$. parahaemolyticus, more than $25 \%$ of the foodborne outbreak caused by the consumption of contaminated seafood has been linked to this bacterium (Alam et al., 2002).

\section{Detection of Vibrio parahaemolyticus in food}

\subsection{Conventional method}

The most probable number (MPN) is one of the common methods used to detect and enumerate $V$. parahaemolyticus in food samples, but the method is time-consuming and tedious. In order to improve sensitivity and detection, alkaline peptone water serves as an enrichment broth for $V$. parahaemolyticus because it has a $\mathrm{pH}$ level (8.5-9) which supports the growth of $V$. parahaemolyticus and a high sodium chloride content $(\mathrm{NaCl})$ thereby inhibiting the growth of other bacteria (DePaola and Kaysner, 2004). Other selective broths used in place of APW are salt polymyxin broth (SPB), alternative protein source (APS) broth, salt colistin broth, glucose salt teepol broth and bile salt sodium taurocholate broth (Bisha et al., 2012). TCBS is the most widely used selective agar for detection of $V$. parahaemolyticus and more preferred because of its sucrose/bromothymol blue diagnostic system which separates sucrose positive Vibrios such as $V$. cholerae from other forms of Vibrio. V. cholerae will produce a yellow colony on TCBS agar (Mrityunjoy et al., 2013) while $V$. parahaemolyticus will produce a green or bluegreen colony on TCBS agar (Bisha et al., 2012). With several studies on the detection of $V$. parahaemolyticus from seafood, scientists have not been able to differentiate between the colonies of $V$. parahaemolyticus from other Vibrio colonies on TCBS agar since TCBS is a general selective media for all Vibrio spp. (Bisha et al., 2012). Therefore, a new enrichment and selective agar solely for the identification of $V$. parahaemolyticus in seafood was discovered by Hara-Kudo et al (2001). The samples were enriched in SPB and streaked on chromogenic CHROMagar. The CHROMagar is made of a colourimetric substrate for $\beta$-galactosidase and produced mainly for the identification of ortho-nitrophenyl $\beta$ galactosidase-positive $V$. parahaemolyticus from another identical Vibrio spp. (Bisha et al., 2012). $V$. parahaemolyticus produce a mauve colour on CHROMagar which makes it easier to differentiate from other Vibrio species. Therefore, several scientists have concluded that CHROMagar gives more sensitive than TCBS agar in detecting $V$. parahaemolyticus ( $\mathrm{Su}$ and Liu, 2007). In addition, $V$. parahaemolyticus can also be detected via colony hybridization. This process involves counting the bacteria on agar plates and confirming the bacteria counted via DNA hybridization. In most cases, every bacterium has its own probes based on variable regions of the 16S rRNA (Thompson et al., 2004). Several studies have shown the counting of bacteria using the radioactive DNA probes or non-radioactive DNA probes in colony hybridization (Deepanjali et al., 2005). Thus, colony hybridization is mainly used to ascertain the identity and amount of pathogenic $V$. parahaemolyticus present in seafood (Suffredini et al., 2014).

\subsection{Kanagawa test}

Thermostable direct hemolysin $(t d h)$ is one of the 
pathogenic gene that influences the production of a distinct hemolytic ring on blood cell agar plates in high salt concentration with D- mannitol as carbon source and this process is called the Kanagawa phenomenon (KP) (Nishibuchi and Kaper, 1995). In past studies, KP was the benchmark for the identification of pathogenic and non-pathogenic $V$. parahaemolyticus strains (Ono et al., 2006) but this method is not realistic, time-wasting and a lot of samples are used (Wang et al., 2011). The Wagatsuma agar consists of human or rabbit blood with $\mathrm{NaCl}$, mannitol, crystal violet and $\mathrm{K}_{2} \mathrm{HPO}_{4}$. This agar is mainly used to differentiate between the $t d h$ and non-tdh strains. Since $V$. parahaemolyticus strains containing the $t d h$ gene will break down the Wagatsuma agar (Alipour et al., 2014). Therefore, the development of a more sensitive and rapid method for identification and detection is important for the general well-being of the public.

\subsection{PCR Detection}

Polymerase chain reaction (PCR) is a reliable and easy way for distinguishing specific pathogenic bacteria. Multiplex PCR targets the toxR, tlh, tdh, trh of $V$. parahaemolyticus from environmental and clinical samples (Paydar et al., 2013). The PCR technique is highly sensitive and specific when detecting virulent bacteria from clinical and environmental samples (Nelapati et al., 2012). The tox $\mathrm{R}$ gene stimulates the formation of $t d h$ gene which is found in pathogenic or non-pathogenic $V$. parahaemolyticus isolates (Sujeewa et al., 2009). In some cases, the thermolabile hemolysin (tlh) in $V$. parahaemolyticus can be used to produce a multiplex PCR technique for the detection of pathogenic $V$. parahaemolyticus (Yi et al., 2014). Although, th is not recognised as a virulent gene in $V$. parahaemolyticus but it is a threshold of the bacteria (Su and Liu, 2007). The multiplex PCR assay is a recognized and most used method for distinguishing between $V$. parahaemolyticus, $V$. cholerae and $V$. alginolyticus and the real-time PCR can be used to process a large number of samples and it gives a consistent result in amplifying the targeted gene (Wei et al., 2014). In recent times, PCR has been used in different fields of study such as forensics, molecular biology, molecular evolution, sequencing, genome mapping and even in diagnosing hereditary diseases.

PCR was first developed by Kary Mullis in 1983 and is now used worldwide due to its availability, flexibility and versatility. PCR is often used for the swift detection of $V$. parahaemolyticus and its virulence gene. The PCR enables for swift amplification of specific DNA fragments from several pools of DNA by detecting its accumulation in real-time by measuring the increase in a fluorescent signal. The technique works by amplifying
DNA fragments by using the DNA polymerase and two primers and then the agarose gel electrophoresis is used to detect the amplified fragments. A serogroup-Ospecific PCR assay was used in the isolation and identification of $V$. parahaemolyticus from clinical and environmental samples (Chen et al., 2012). The multiplex real-time PCR with separate fluorescent probes was used in detecting pathogenic $V$. parahaemolyticus in different seafood (Robert-Pillot et al., 2010). A quantitative PCR technique with propidium monoazide has been used to amplify the viable $V$. parahaemolyticus cells in raw seafood (Zhu et al., 2012). Therefore, detection of $V$. parahaemolyticus using PCR gives a rapid result which is very accurate, but the PCR cycler needs to be optimized frequently to get an accurate result (Letchumanan et al., 2014).

With different technology advancement, Loopmediated isothermal amplification (LAMP) has been developed for the detection of $V$. parahaemolyticus and often used in place of the PCR (Notomi et al., 2000). It is a technique for DNA amplification under isothermal condition using specific primers (Qi et al., 2012). The benefit of the LAMP-based assay to the PCR is that during LAMP, amplification of nucleic acid takes place at a single temperature, thus the thermal cycler is not needed. The LAMP is used to identify $t d h$-positive isolates of $V$. parahaemolyticus targeting six regions of the $t d h$ gene and comparing the results to PCR for detection of $t d h$ and reverse passive latex agglutination for $t d h$ detection (Nemoto et al., 2009). A novel LAMP in its original place was used in identifying $V$. parahaemolyticus strains and it gave a more rapid detection with high accuracy and less time compared to the regular LAMP and other PCR techniques (Wang, Shi, Su et al., 2013). In a recent study, Zeng et al. (2014) developed a novel LAMP-based method that combines the LAMP assay with immunomagnetic separation to identify $V$. parahaemolyticus in raw oysters.

Nevertheless, LAMP is a cost-effective method to detect pathogenic bacteria at a single temperature without using a cycler like the PCR, but the methods of targeted separation and enrichments influence the application of LAMP. In addition, the rpoD and toxR gene of $V$. parahaemolyticus strains were identified using the LAMP assay and this method gave an accurate result of 3.7 and $459 \mathrm{CFU}$ per test in pure culture (Nemoto et al., 2011).

\subsection{Immunological detection}

The immunological detection method is often used for the swift identification and measurement of foodborne pathogens present in seafood. This method is dependent on the monoclonal antibodies of the pathogen. 
Sandwich enzyme-linked immunosorbent assays based on monoclonal antibodies directed against $t d h$, $t r h$, th are used to detect these proteins in virulent clinical isolates of $V$. parahaemolyticus (Sakata et al., 2012). Although, monoclonal antibodies are not enough to detect all environmental and clinical $V$. parahaemolyticus strains because other bacteria present in the samples can interfere with the process thereby giving a false interpretation (Prompamorn et al., 2013). In recent times, the use of recombinant antibody fragments like the single-chain variable fragments (scFvs) is important for researching, identifying and treating diseases (Wang et al., 2014). Wang et al. (2012) concealed a virulent tlh $V$. parahaemolyticus strain in a high affinity $\mathrm{scFv}$ antibody. The concealed $\mathrm{scFv}$-LA3 antibody is active against the th $V$. parahaemolyticus strain. The scFv-LA3 precisely identified the th produced by the $V$. parahaemolyticus (Wang et al., 2014). Therefore, this method can be used to detect the th V. parahaemolyticus strains in seafood (Wang et al., 2012).

\section{Conclusion}

$V$. parahaemolyticus is a bacterium naturally occurring in marine and estuarine habitat and a leading cause of seafood-borne diseases. The research about the health implications of $V$. parahaemolyticus will most likely continue in future as long as seafood remains the vehicle of transmission of this bacterium. $V$. parahaemolyticus possess several virulence factors that cause hemolytic activity, gastroenteritis and sometimes death. The pathogenicity of $V$. parahaemolyticus is dependent on its virulence factors. Therefore, it is essential to gather more knowledge on the different virulence factors and how to regulate them. The high occurrence of antibiotic resistant $V$. parahaemolyticus in the marine environment is due to the continuous exposure to conventionally used antibiotics. Therefore, it is important to implement the use of probiotics in order to reduce the use of antibiotics thereby reducing threats to public health. The consistent outbreak of $V$. parahaemolyticus shows that the existing preventive measures to control the infection have not been effective as the infection continues to occur annually. Thus, it is important to develop a coordinated measure to eradicate the occurrence of the infections. Many detection methods are used in isolating and identifying $V$. parahaemolyticus depending on its virulence factors. Nonetheless, the PCR method gives a rapid, reliable, and more efficient result.

\section{Conflict of interest}

The authors declare no conflict of interest.

\section{Acknowledgements}

This research was financially supported by the International Foundation of Sciences, Sweden (E- 52372F). The authors appreciated the technical support provided by the staff from the Faculty of Bioresources and Food Industry.

\section{References}

Alam, M.J., Tomochika, K.I., Miyoshi, S.I. and Shinoda, S. (2002). Environmental investigation of potentially pathogenic Vibrio parahaemolyticus in the SetoInland Sea, Japan. FEMS Microbiology Letters, 208 (1), 83-87. https://doi.org/10.1111/j.15746968.2002.tb11064.x

Al-Othrubi, S.M.Y., Kqueen, C.Y., Mirhosseini, H., Hadi, Y.A. and Radu, S. (2014). Antibiotic Resistance of Vibrio parahaemolyticus isolated from cockles and shrimp seafood marketed in Selangor, Malaysian. Clinical Microbiology: Open Access, 3 (3), 1000148

Alipour, M., Issazadeh, K. and Soleimani, J. (2014). Isolation and identification of Vibrio parahaemolyticus from seawater and sediment samples in the southern coast of the Caspian Sea. Comparative Clinical Pathology, 23, 129-133. https://doi.org/10.1007/s00580-012-1583-6

Ansaruzzaman, M., Chowdhury, A., Bhuiyan, N.A., Sultana, M., Safa, A. and Lucas, M. (2008). Characteristics of a pandemic clone of O3:K6 and O4:K68 Vibrio parahaemolyticus in Beira, Mozambique. Journal of Medical Microbiology, 57 (12), 1502-1507. https://doi.org/10.1099/ jmm.0.2008/004275-0

Bilung, L.M., Radu, S., Bahaman, A.R., Abdul Rahim, R., Napis, S., Ling, M.W., Tani, G.B. and Nishibuchi, M. (2005). Detection of Vibrio parahaemolyticus in cockle (Anadara granosa) by PCR. FEMS Microbiology Letters, 252(1), 85-88. https://doi.org/10.1016/j.femsle.2005.08.053

Bisha, B., Simonson, J., Janes, M., Bauman, K. and Goodridge, L.D. (2012). A review of the current status of cultural and rapid detection of Vibrio parahaemolyticus. International Journal of Food Science Technology, 47(5), 855-899. https:// doi.org/10.1111/j.1365-2621.2012.02950.x

Broberg, C.A., Calder, T.J. and Orth, K. (2011). Vibrio parahaemolyticus cell biology and pathogenicity determinants. Microbes Infection, 13(12-13), 9921001. https://doi.org/10.1016/j.micinf.2011.06.013

CDC (Centers for Disease Control and Prevention). (2018). Carbapenemase Producing CarbapenemResistant Enterobacteriaceae (CP-CRE). Atlanta, 
GA: Centers for Disease Control and Prevention.

Ceccarelli, D., Hasan, N.A., Hug, A. and Colwell, R.R. (2013). Distribution and dynamics of epidemic and pandemic Vibrio parahaemolyticus virulence factors. Frontiers in Cellular and Infection Microbiology, 3, 97. https://doi.org/10.3389/fcimb.2013.00097

Chen, M.B., Guo, D., Wong, H.C., Zhang, X., Liu, F. X., Chen, H.Y., Chen, M., Liu, B., Wang, L., Wu, F. and Feng. L. (2012). Development of O-serogroup specific PCR assay for detection and identification of Vibrio parahaemolyticus. International Journal of Food Microbiology, 159(2), 122-129. https:// doi.org/10.1016/j.ijfoodmicro.2012.08.012

Dean, P. (2011). Functional domains and motifs of bacterial type III effector proteins and their roles in infection. FEMS Microbiology Reviews, 35(6), 1100 -1125 . https://doi.org/10.1111/j.15746976.2011.00271.x

Deepanjali, A., Sanath Kumar, H. and Karunasagar, I. (2005). Seasonal variation in abundance of total and pathogenic Vibrio parahaemolyticus bacteria in oysters along the southwest coast of India. Applied and Environmental Microbiology, 71(7), 3575-3580. https://doi.org/10.1128/AEM.71.7.3575-3580.2005

DePaola, A. and Kaysner, C.A. (2004). Vibrio. Bacteriological Analytical Manual Online. Washington, DC: U.S. Food and Drug Administration.

FAO. (2016). Drivers, Dynamics and epidemiology of antimicrobial resistance in animal production. Retrieved from FAO website: http://www.fao.org/3/a -i6209e.pdf

Gode-Potratz, C.J, Kustusch, R.J, Breheny, P.J, Weiss, D.S. and McCarter, L.L. (2011). Surface sensing in Vibrio parahaemolyticus triggers a programme of gene expression that promotes colonization and virulence. Molecular Microbiology, 79(1), 240-263. https://doi.org/10.1111/j.1365-2958.2010.07445.x

González-Escalona, N., Martinez-Urtaza, J., Romero, J., Espejo, R.T., Jaykus, L.A. and DePaola, A. (2008). Determination of molecular phylogenetics of Vibrio parahaemolyticus strains by multilocus sequence typing. Journal of Bacteriology, 190, 2831-2840. https://doi.org/10.1128/JB.01808-07

Gu, W., Yin, J., Yang, J., Li, C., Chen, Y., Yin, J., Xu, W., Zhao, S., Liang, J., Jing, H. and Fu, X. (2014). Characterization of Vibrio cholerae from 1986 to 2012 in Yunnan Province, southwest China bordering Myanmar. Infection, Genetic and Evolution, 21, 1-7. https://doi.org/10.1016/ j.meegid.2013.10.015

Gutierrez West, C.K., Klein, S.L. and Lovell, C.R.
(2013). High frequency of virulence factor genes $t d h$, trh and th in Vibrio parahaemolyticus strains isolated from a pristine estuary. Applied and Environmental Microbiology, 79, 2247-2252. https://doi.org/10.1128/AEM.03792-12

Ham, H. and Orth, K. (2012). The role of type III secretion system in Vibrio parahaemolyticus pathogenicity. Journal of Microbiology, 50, 719725. https://doi.org/10.1007/s12275-012-2550-2

Hara-Kudo, Y., Nishina, T., Nakagawa, H., Konuma, H., Hasegawa, J. and Kumagai, S. (2001). Improved method for detection of Vibrio parahaemolyticus in seafood. Applied and Environmental Microbiology, 67, 5819-5823. https://doi.org/10.1128/ AEM.67.12.5819-5823.2001

Hara-Kudo, Y., Saito, S., Ohtsuka, K., Yamasaki, S., Yahiro, S. and Nishio, T. (2012). Characteristics of a sharp decrease in Vibrio parahaemolyticus infections and seafood contamination in Japan. International Journal of Food Microbiology, 157(1), 95-101. https://doi.org/10.1016/j.ijfoodmicro.2012.04.019

Hernández-Díaz, L., Leon-Sicairos, N., VelazquezRoman, J., Flores-Villaseñor, H., Guadron-Llanos, A.M. and Martinez-Garcia, J.J. (2015). A pandemic Vibrio parahaemolyticus O3:K6 clone causing most associated diarrhea cases in the Pacific Northwest coast of Mexico. Frontiers in Microbiology, 6, 221. https://doi.org/10.3389/ fmicb.2015.00221

Iwamoto, M., Ayers, T., Mahon, B.E. and Swerdlow, D.L. (2010). Epidemiology of seafood associated infections in the United States. Clinical Microbiology Reviews, 23, 399-411. https:// doi.org/10.1128/CMR.00059-09

Jones, J.L., Ludeke, C.H.M., Bowers, J.C., Garrett, N., Fischer, M. and Parsons, M.B. (2012). Biochemical, serological and virulence characterization of clinical and oyster Vibrio parahaemolyticus isolates. Journal of Clinical Microbiology, 50, 2343-2352. https:// doi.org/10.1128/JCM.00196-12

Khan, A.A., McCarthy, S., Wang, R.F. and Cerniglia, C.E. (2002). Characterization of united states outbreak isolates of Vibrio parahaemolyticus using Enterobacterial Repetitive Intergenic Consensus (ERIC) PCR and development of a rapid PCR method for detection of isolates. FEMS Microbiology Letters, 206(2), 209-214. https:// doi.org/10.1111/j.1574-6968.2002.tb11011.x

Kim, J.J. and Jo, E.K. (2013). NLRP3 inflammasome and host protection against bacterial infection. Journal of Korean Medical Science, 28, 1415-1423. https://doi.org/10.3346/jkms.2013.28.10.1415 
Krachler, A.M. and Orth K. (2011). Functional characterization of the interaction between bacterial adhesin multivalent adhesion molecule 7 (MAM7) protein and its host cell ligands. Journal of Biological Chemistry, 286(45), 38939-38947. https://doi.org/10.1074/jbc.M111.291377

Lee, L.H. and Raghunath, P. (2018). Editorial: Vibrionaceae diversity, multidrug resistance and management. Frontiers in Microbiology, 9, 563. https://doi.org/10.3389/fmicb.2018.00563

Letchumanan, V., Chan, K.G. and Lee, L.H. (2014). Vibrio parahaemolyticus: A review on the pathogenesis, prevalence and advance molecular identification techniques. Frontiers in Microbiology, 5, 705. https://doi.org/10.3389/fmicb.2014.00705

Letchumanan, V., Yin, W.F., Lee, L.H. and Chan, K.G. (2015). Occurrence and antibiotic resistance of Vibrio parahaemolyticus from shellfish in Selangor, Malaysia. Frontiers in Microbiology, 6, 1417. https://doi.org/10.3389/fmicb.2015.01417

Li, J., Xue, F., Yang, Z., Zhang, X., Zeng, D. and Chao, G. (2016). Vibrio parahaemolyticus strains of pandemic serotypes identified from clinical and environmental samples from Jiangsu, China. Frontiers in Microbiology, 7, 787. https:// doi.org/10.3389/fmicb.2016.00787

Lim, J., Stones, D.H., Hawley, C.A., Watson, C.A. and Krachler, A.M. (2014). Multivalent adhesion molecule 7 clusters act as signaling platform for host cellular GTPase activation and facilitate epithelial barrier dysfunction. PLoS Pathogens, 10(9), e1004421. https://doi.org/10.1371/ journal.ppat.1004421

Liu, M. and Chen, S. (2015). A novel adhesive factor contributing to the virulence of Vibrio parahaemolyticus. Scientific Reports, 5, 14449. https://doi.org/10.1038/srep14449

Malcolm, T.T.H, Cheah, Y.K, Radzi, C.W.J.W.M, Kasim, F.A, Kantilal, H.K. and John, T.Y.H. (2015). Detection and quantification of pathogenic Vibrio parahaemolyticus in shellfish by using multiplex PCR and loop-mediated isothermal amplification assay. Food Control, 47, 664-671. https:// doi.org/10.1016/j.foodcont.2014.08.010

Martin, A., Fahrbach, K., Zhao, Q. and Lodise, T. (2018). Association between carbapenem resistance and mortality among adult, hospitalized patients with serious infections dues to Enterobacteriaceae: Results of systematic literature review and metaanalysis. Open Forum Infectious Diseases, 5(7), ofy150. https://doi.org/10.1093/ofid/ofy150

Martinez-Urtaza, J., Simental, L., Velasco, D., DePaola,
A., Ishibashi, M. and Nakaguchi, Y. (2005). Pandemic Vibrio parahaemolyticus O3:K6, Europe. Journal of Emerging Infectious Disease, 11, 13191320. https://doi.org/10.3201/eid1108.050322

Mrityunjoy, A., Kaniz, F., Fahmida, J., Shanzida, J.S., Md-Aftab, U. and Rashed, N. (2013). Prevalence of Vibrio cholerae in different food samples in the city of Dhaka, Bangladesh. International Food Research Journal, 20(2), 1017-1022.

Nair, G.B., Ramamurthy, T., Bhattacharya, S.K., Dutta, B., Takeda, Y. and Sack, D.A. (2007). Global dissemination of Vibrio parahaemolyticus serotype O3:K6 and its serovariants. Clinical Microbiology Reviews, 20, 39-48. https://doi.org/10.1128/ CMR.00025-06

Nelapati, S., Nelapati, K. and Chinnam, B.K. (2012). Vibrio parahaemolyticus- An emerging foodborne pathogen - A Review. Veterinary World, 5(1), 4862. https://doi.org/10.5455/vetworld.2012.48-63

Nemoto, J., Sugawara, C., Akahane, K., Hashimoto, K., Kojima, T. and Ikedo, M. (2009). Rapid and specific detection of the thermostable direct hemolysin gene in Vibrio parahaemolyticus by loop-mediated isothermal amplification. Journal of Food Protection, 72(4), 748-754. https:// doi.org/10.4315/0362-028X-72.4.748

Nemoto, J., Ikedo, M., Kojima, T., Momoda, T., Konuma, H. and Hara-Kudo, Y. (2011). Development and evaluation of a loop mediated isothermal amplification assay for rapid and sensitive detection of Vibrio parahaemolyticus. Journal of Food Protection, 74(9), 1462-1467. https://doi.org/10.4315/0362-028X.JFP-10-519

Nishibuchi, M. and Kaper, J.B. (1995). Thermostable direct hemolysin gene of Vibrio parahaemolyticus: a virulence gene acquired by a marine bacterium. Infectious Immunity, 63, 2093-2099. https://doi.org/10.1128/IAI.63.6.2093-2099.1995

Notomi, T., Okayama, H., Masubuchi, H., Yonekawa, Watanabe, K. and Amino, N. (2000). Loop mediated isothermal amplification of DNA. Nucleic Acids Research, 28(12), e63. https://doi.org/10.1093/ nar/28.12.e63

Ono, T., Park, K.S., Ueta, M., Iida, T. and Honda, T. (2006). Identification of proteins secreted via Vibrio parahaemolyticus type III secretion system 1. Infection and Immunity, 74, 1032-1042. https:// doi.org/10.1128/IAI.74.2.1032-1042.2006

Paranjpye, R., Hamel, O.S., Stojanovski, A. and Liermann, M. (2012). Genetic diversity of clinical and environmental Vibrio parahaemolyticus strains from the Pacific Northwest. Applied and 
Environmental Microbiology, 78, 8631-8638. https://doi.org/10.1128/AEM.01531-12

Paydar, M., Teh, C.S.J. and Thong, K.L. (2013). Prevalence and characterization of potentially virulent Vibrio parahaemolyticus in seafood in Malaysia using conventional methods, PCR and REP -PCR. Food Contamination, 32(1), 13-18. https:// doi.org/10.1016/j.foodcont.2012.11.034

Pazhani G.P., Bhowmik S. K., Ghosh S., Guin S., Dutta S., Rajendran K., Saha D.R., Nandy, R.K., Bhattacharya, M.K., Mukhopadhay, A.K. and Ramamurthy, T. (2014). Trends in the epidemiology of pandemic and non-pandemic strains of Vibrio parahaemolyticus isolated from diarrheal patients in Kolkata, India. PLoS Neglected Tropical Diseases, 8 (5), e2815. https://doi.org/10.1371/ journal.pntd.0002815

Prompamorn, P., Longyant, S., Pengsuk, C., Sithigorngul, P. and Chaivi-suthangkura, P. (2013). Rapid identification and differentiation of Vibrio parahaemolyticus from Vibrio spp. in seafood samples using developed monoclonal antibodies. World Journal of Microbiology and Biotechnology, 29, 721-731. https://doi.org/10.1007/s11274-0121228-6

Qi, J., Du, Y., Zhu, R., Zhu, X., Bai, H. and Hu, M. (2012). A loop-mediated isothermal amplification method for rapid detection of the multidrugresistance gene cfr. Gene, 504(1), 140-143. https:// doi.org/10.1016/j.gene.2012.04.049

Raghunath, P. (2015). Roles of thermostable direct hemolysin (TDH) and TDH-related hemolysin (TRH) in Vibrio parahaemolyticus. Frontiers in Microbiology, 5, 805. https://doi.org/10.3389/ fmicb.2014.00805

Robert-Pillot A., Copin S., Gay M., Malle P. and Quilici M.L. (2010). Total and pathogenic Vibrio parahaemolyticus in shrimp: fast and reliable quantification by real time PCR. International Journal of Food Microbiology, 143(3), 190-197. https://doi.org/10.1016/j.ijfoodmicro.2010.08.016

Sahilah, A.M., Laila, R.A., Sallehuddin, H.M., Osman, H., Aminah, A. and Ahmah Azuhairi, A. (2014). Antibiotic resistance and molecular typing among cockle (Anadara granosa) strains of Vibrio parahaemolyticus by polymerase chain reaction (PCR)-based analysis. World Journal of Microbiology and Biotechnology, 30, 649-659. https://doi.org/10.1007/s11274-013-1494-y

Saito, S., Iwade, Y., Tokuoka, E., Nishio, T., Otomo, Y., Araki, E., Konuma, H., Nakagawa, H., Tanaka, H., Sugiyama, K., Hasegawa, A., Sugita-Konishi, Y. and Hara-Kudo, Y. (2015). Epidemiological evidence of lesser role of thermostable direct hemolysin (TDH)related hemolysin (TRH) than TDH on Vibrio parahaemolyticus pathogenicity. Foodborne Pathogens and Disease, 12, 131-138. https:// doi.org/10.1089/fpd.2014.1810

Sakata, J., Kawatsu, K., Kawahara, R., Kanki, M., Iwasaki, T. and Kumeda, Y. (2012). Production and characterization of a monoclonal antibody against recombinant thermolabile hemolysin and its application to screen for Vibrio parahaemolyticus contamination in raw seafood. Food Control, 23(1), 171-176.

https://doi.org/10.1016/ j.foodcont.2011.07.005

Sawabe, T., Ogura, Y., Matsumura, Y., Gao. F., Amin, A.K.M., Mino, S., Nakagawa, S., Sawabe, T., Kumar, R., Fukui, Y. and Satomi, M. (2013). Updating the Vibrio clades defined by multilocus sequence phylogeny: proposal of eight new clades and the description of Vibrio tritonius sp. nov. Frontiers in Microbiology, 4, 414. https:// doi.org/10.3389/fmicb.2013.00414

Scallan, E., Hoekstra, R.M., Angulo, E.J., Tauxe, R.V., Widdowson, M., Roy, S.L., Jones, J.I. and Grithin, P.M. (2011). Foodborne illness acquired in the united states. Major pathogens Emerging Infectious Disease, 37(1), 7-15. https://doi.org/10.3201/ eid1701.P11101

Shimohata, T. and Takahashi, A. (2010). Diarrhea induced by infection of Vibrio parahaemolyticus. Journal of Medical Internet Research, 57(3), 179182. https://doi.org/10.2152/jmi.57.179

Stones, D.H. and Krachler, A.M. (2015). Dual function of a bacterial protein as an adhesin and extracellular effector of host GTPase signaling. Small GTPases, 6 (3), 153-156. https:// doi.org/10.1080/21541248.2015.1028609

Su, C.Y. and Liu, C. (2007). Vibrio parahaemolyticus: a concern of seafood safety. Microbiological Research Elsevier, 24(6), 549-558. https://doi.org/10.1016/ j.fm.2007.01.005

Sudha, S., Mridula, C., Silvester, R. and Hatha, A.A.M. (2014). Prevalence and antibiotic resistance of pathogenic Vibrios in shellfishes from Cochin market. Indian Journal of Geo-Marine Sciences, 43 (5), 815-824

Suffredini, E., Cozzi, L., Ciccaglioni, G. and Croci, L. (2014). Development of a colony hybridization method for the enumeration of total and potentially enteropathogenic Vibrio parahaemolyticus in shellfish. International Journal of Food Microbiology, 186, 22-31. https://doi.org/10.1016/ j.ijfoodmicro.2014.06.009 
Sujeewa, A.K.W., Norrakiah, A.S. and Laina, M. (2009). Prevalence of toxic genes of Vibrio parahaemolyticus in shrimps (Penaeus monodon) and culture environment. International Journal of Food Research, 16, 89-95.

Syamimi-Hanim, M.-S. and Tang, J.Y.H. 2019. Detection and characterization of Vibrio parahaemolyticus in raw mackerel fish and fishbased street food. Bioscience Research, 16(SI), 174181.

Tang, J.Y.H., Wan-Rosli, W.F., Abdul-Razak, N.H., Yeo, C.C., Abu Bakar, C.A. and Son, R. (2014). Incidence and antibiogram of Vibrio parahaemolyticus in processed and frozen bivalve mollusks in Kuala Terengganu, Malaysia. International Food Research Journal, 21(3), 13491353

Thompson, F.L., Lida, T. and Swings, J. (2004). Biodiversity of Vibrios. Microbiology and Molecular Biology Reviews, 68, 403-431. https:// doi.org/10.1128/MMBR.68.3.403-431.2004

USDA (United States Department of Agriculture) (2016). Import share of consumption. Retrieved from USDA website: http://www.ers.usda.gov/topics/ international-markets-trade/us-agricultural-trade/ import-share-ofconsumption

Van Hoek, A.H.A.M., Mevius, D., Guerra, B., Mullany, P., Roberts, A.P. and Aarts, H.J.M. (2011). Acquired antibiotic resistance genes: An overview. Frontiers in Microbiology, 2, 203. https://doi.org/10.3389/ fmicb.2011.00203

Velazquez-Roman, J., Leon-Sicairos, N., FloresVillasenor, H., Villafana-Rauda, S. and CanizalezRoman, A. (2012). Association of pandemic Vibrio parahaemolyticus $\mathrm{O} 3: \mathrm{K} 6$ present in the coastal environment of Northwest Mexico with cases of recurrent diarrhea between 2004 and 2010. Applied and Environmental Microbiology, 78, 1794-1803. https://doi.org/10.1128/AEM.06953-11

Velazquez-Roman, J., León-Sicairos, N., de Jesus Hernández-Díaz, L. and Canizalez-Roman, A. (2014). Pandemic Vibrio parahaemolyticus O3:K6 on the American continent. Frontiers in Cellular and Infection Microbiology, 3, $110 . \quad \mathrm{https} / /$ doi.org/10.3389/fcimb.2013.00110

Wang, H.P., Zhang, J.L., Jiang, T., Bao, Y.X. and Zhou, X.M. (2011). Insufficiency of the Kanagawa hemolytic test for detecting pathogenic Vibrio parahaemolyticus in Shanghai, China. Diagnostic Microbiology and Infectious Disease, 69(1), 7-11. https://doi.org/10.1016/j.diagmicrobio.2010.08.016

Wang, R.Z., Fang, S., Wu, D.L., Wu, D., Lian, J. and Fan, J. (2012). Screening of a ScFv antibody that can neutralize effectively the cytotoxicity of Vibrio parahaemolyticus TLH. Applied and Environmental Microbiology, 78, 4967-4975. https:// doi.org/10.1128/AEM.00435-12

Wang, L., Shi, L., Su, J.Y., Ye, Y.X. and Zhong, Q.P. (2013). Detection of Vibrio parahaemolyticus in food samples using in-situ loop-mediated isothermal amplification method. Gene, 515(2), 421-425. https://doi.org/10.1016/j.gene.2012.12.039

Wang, R.Z., Xiang, S.S., Feng, Y.J., Srinivas, S., Zhang, Y.F. and Lin, M.S. (2013). Engineering production of functional $\mathrm{scFv}$ antibody in $E$. coli by coexpressing the molecule chaperone Skp. Frontiers in Cellular and Infection Microbiology, 3, 72. https:// doi.org/10.3389/fcimb.2013.00072

Wang, R.Z., Xiang, S.S., Zhang, Y.H., Chen, Q.Y., Zhong, Y.F. and Wang, S.H. (2014). Development of a functional antibody by using a green fluorescent protein frame as the template. Applied and Environmental Microbiology, 80, 4126-4137. https://doi.org/10.1128/AEM.00936-14

Wang, R., Zhong, Y., Gu, X., Yuan, J., Saeed, A.F. and Wang, S. (2015). Corrigendum: The pathogenesis, detection and prevention of Vibrio parahaemolyticus. Frontiers in Microbiology, 6, 437. https://doi.org/10.3389/fmicb.2015.00437

Weese, J.S., Giguère, S., Guardabassi, L., Morley, P.S., Papich, M. and Ricciuto, D.R. (2015). ACVIM consensus statement on therapeutic antimicrobial use in animals and antimicrobial resistance. Journal of Veterinary International Medicine, 29(2), 487-498. https://doi.org/10.1111/jvim.12562

Wei, S., Zhao, H., Xian, Y., Hussain, M.A. and Wu, X. (2014). Multiplex PCR assays for the detection of Vibrio alginolyticus, Vibrio parahaemolyticus, Vibrio vulnificus and Vibrio cholerae with an internal amplification control. Diagnostic Microbiology Infectious Disease, 79(2), 115-118. https://doi.org/10.1016/j.diagmicrobio.2014.03.012

Witus, I.W. and Van, L.W. (2016). Aquaculture in Malaysia: A short review on current policy and legislation. Transactions Science Technology, 3(1-2), 150-154.

Xie, T., Wu, Q., Zhang, J., Xu, X. and Cheng, J. (2017). Comparison of Vibrio parahaemolyticus isolates from aquatic products and clinical by antibiotic susceptibility, virulence and molecular characterization. Food Control, 71, 315-321. https:// doi.org/10.1016/j.foodcont.2016.06.046

Xu, X., Wu, Q., Zhang, J., Cheng, J., Zhang, S. and Wu, K. (2014). Prevalence, pathogenicity and serotypes of Vibrio parahaemolyticus in shrimp from Chinese retail markets. Food Control, 46, 81-85. https:// 
doi.org/10.1016/j.foodcont.2014.04.042

Yeung, P.S. and Boor, K.J. (2004). Epidemiology, pathogenesis and prevention of food borne vibrio parahaemolyticus infection. Foodborne Pathogens and Diseases, 1, 74-88. https:// doi.org/10.1089/153531404323143594

Yi, M.Y., Ling, L., Neogi, S.B., Fan, Y., Tang, D.Y. and Yamasaki, S. (2014). Real time loop- mediate isothermal amplification using a portable fluorescence scanner for rapid and simple detection of Vibrio parahaemolyticus. Food Control, 41, 9195. https://doi.org/10.1016/j.foodcont.2014.01.005

Zarei, M., Borujeni, M.P., Jamnejad, A. and Khezrzadeh, M. (2012). Seasonal prevalence of Vibrio species in retail shrimps with an emphasis on Vibrio parahaemolyticus. Food Control, 25(1), 107109. https://doi.org/10.1016/j.foodcont.2011.10.024

Zeng, J., Wei, H., Zhang, L, Liu, X., Zhang, H. and Cheng, J. (2014). Rapid detection of Vibrio parahaemolyticus in raw oysters using immunomagnetic separation combined with loopmediated isothermal amplification. International Journal of Food Microbiology, 174, 123-128. https://doi.org/10.1016/j.ijfoodmicro.2014.01.004

Zhao, X., Li, Y., Wang, L., You, L., Xu, Z. and Li, L. (2011) Development and application of a loopmediated isothermal amplification method on rapid detection of Pseudomonas aeruginosa strains. World Journal of Microbiology and Biotechnology, 27, 181 -184. https://doi.org/10.1007/s11274-010-0429-0

Zheng, Y., Wu, Q., Wu, K., Zhang, J., Guo, W. and Wu, K. (2014). Virulence associated gene detection and ERIC-PCR typing of Campylobacter jejuni strains isolated from foods in four Southern Chinese provinces. Acta Microbiologica Sinica, 54(1), 1423.

Zhu, R.G., Li, T.P., Jia, Y.F. and Song, L.F. (2012). Quantitative study of viable Vibrio parahaemolyticus cells in raw seafood using propidium monoazide in combination with quantitative PCR. Journal of Microbiological Methods, 90(3), 262-266. https://doi.org/10.1016/ j.mimet.2012.05.019 